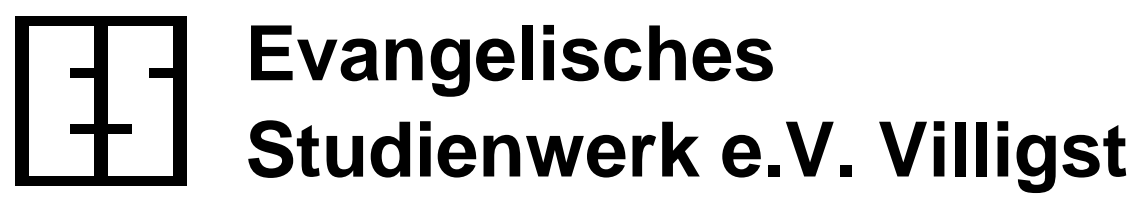
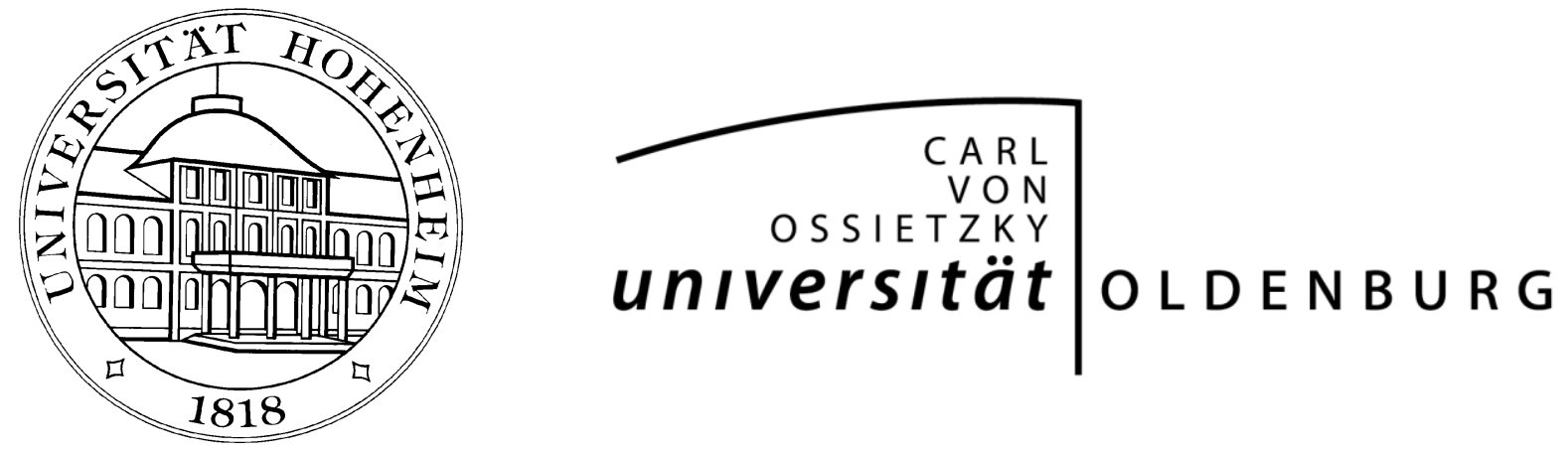

Schriftenreihe des Promotionsschwerpunkts

Globalisierung und Beschäftigung

Nr. 45/2015

Stylized Facts of the Business Cycle:

Universal Phenomenon, or Institutionally

Determined?

von

Vadim Kufenko und Niels Geiger

Stuttgart-Hohenheim

ISSN 1618-5358 
Unemployment is persistently high in many European countries. It is frequently attributed to 'functional deficiencies of labor markets', even though to a large extent caused by demand and supply shifts in goods markets and financial markets. The $\mathrm{PhD}$ program Globalization and Employment therefore focuses on the employment effects of structural change and macroeconomic developments and encourages research by granting scholarships. The dissertation projects address topics such as new technologies, processes of internationalization and system transformation, endogenous finance constraints and various strategies of fiscal and monetary policy.

Work and supervision in the $\mathrm{PhD}$ program follows the structures of a standard graduate school. Coordinators and editors of the discussion paper series are the following professors:

Prof. Dr. Harald Hagemann

Department of Economics (520H)

University of Hohenheim

D-70593 Stuttgart

Prof. Dr. Heinz-Peter Spahn

Department of Economics (520A)

University of Hohenheim

D-70593 Stuttgart

Prof. Dr. Hans-Michael Trautwein

Department of Economics and Statistics

Carl von Ossietzky University Oldenburg

D-26111 Oldenburg harald.hagemann@uni-hohenheim.de

peter.spahn@uni-hohenheim.de

michael.trautwein@uni-oldenburg.de

$\mathrm{PhD}$ projects in the program can be funded by grants of the Evangelisches Studienwerk e.V. Villigst. Application forms can be ordered from:

Evangelisches Studienwerk e.V.

Promotionsförderung

Iserlohner Str. 25

D-58239 Schwerte

Phone: +49 (2304) 755-215, Fax: +49 (2304) 755-250

For further information about the $\mathrm{PhD}$ program Globalization and Employment as well as the PDF-files of the discussion papers see:

http://www.globalization-and-employment.de 


\title{
Stylized Facts of the Business Cycle: Universal Phenomenon, or Institutionally Determined?
}

\author{
Vadim Kufenko and Niels Geiger* \\ University of Hohenheim, Department of Economics
}

\begin{abstract}
This paper empirically investigates and theoretically reflects on the generality of the "stylized facts" discussed in business cycle analysis. Using OECD data for 1960-2010, the duration of business cycles as well as three models capturing core macroeconomic relations are estimated: based on the Phillips curve (the inflation-unemployment nexus), Okun's law (in the context of the relation between output growth and unemployment) and the inflation-output relation. Results are validated by relevant statistical tests. Observed durations vary from 4 to 8 years, and estimated coefficients differ in signs and magnitudes. Bearing these substantial variations in mind, an explanation of this heterogeneity is attempted by referring to proxies for various institutional variables for the goods, labour and money markets. The findings suggest that core coefficients in the relations, such as the slope of the Phillips curve, show significant correlation with some of these variables, but no uniform results are obtained. In the detailed theoretical discussion and interpretation it is thus argued that the notable differences between countries call the universality of the "stylized facts" into question, but also that these variations cannot be explained exhaustively by the institutional proxy variables employed here.
\end{abstract}

Keywords: business cycles, empirical analysis, institutions, stylized facts

JEL classification: E02, E32, E39, F44

\footnotetext{
${ }^{*}$ University of Hohenheim, Department of Economics, Schloss Osthof-West. Vadim.Kufenko@uni-hohenheim,de; Niels.Geiger@uni-hohenheim.de Telefone numbers: $+4971145923783 ;+4971145922562$.
} 


\section{Introduction}

Research on business cycles has a long and eclectic history both concerning theory and empirical work. If any consensus on the subject is to be pointed out, it is in the conclusion that the business cycle is a phenomenon related to, and appearing in correlation with, a multitude of movements in various economic variables. This applies especially to those aspects of the business cycle which have the longest tradition in the history of economic thought: crises and recessions.

Similarly to Kaldor's (1957) famous "stylized facts" of growth, i.e. the long-term trend movement of an economy, the literature on business cycle research, too, has established a list of "stylized facts" of "movements about trend in gross national product" (Lucas 1977) as well. These observations generally accepted by most theorists in the field build on a long tradition in empirical business cycle research since the seminal work of Wesley C. Mitchell and others, and are used both as a summary of what generally constitutes a business cycle, and as a benchmark to measure existing theories against. As the founder of the National Bureau of Economic Research (NBER), Mitchell's research, as well as newer work on characteristics and predominant traits of business cycles by the NBER, is often focused on developments in the United States. This applies especially to studies involving a longer time frame. There is comparable work on developments in major European countries, no doubt, but much of the discussion still revolves around U.S. trends, and especially comparisons among different countries - and to what degree the stylized facts may or may not accurately describe movements in economic variables over the business cycle there - are relatively rare.

This paper, therefore, tests the universality of these observations on the business cycle by analysing time series for various OECD countries from 1960 to 2010. Section 2 opens the discussion by summarizing and reflecting on the usual list of stylized facts, including the background of the studies they were derived from, and references to other related literature. Section 3 then presents both a descriptive overview and a more extensive statistical analysis of central data touched upon by the stylized facts to answer the question of whether or not, and to what extent, these stylized facts may be found in the time series analyzed here. In a next step, it is then attempted to explain the international differences which become apparent in the study by referring to measures of countries' institutional setups. The results are then discussed theoretically in Section 4, before the last section concludes with a summary of the results derived in this paper and an outlook pointing at further research. 


\section{Theoretical Background and Related Litera- ture}

Business cycle theory is a very wide and varied subject. Already more than a century ago, Werner Sombart (1904) had observed the vast field of various available theories. When Gottfried Haberler (1946) summarized the many different strands and approaches for the League of Nations, this comprehensive effort easily filled hundreds of pages, although it mostly contained only short summaries of the various theories. The approaches developed in subsequent decades - Post-Keynesian at first, then especially Monetarist and New Classical, later New Keynesian - would once again tread on very different paths concerning fundamental theoretical assumptions and even methodology. Until today, therefore, there is neither a unified standard theory of business cycles, nor one that is universally accepted by a wide majority of theorists. In fact, it may even be argued that all those approaches in the Real Business Cycles (RBC) tradition, which have been the standard in applied research for about three decades now, are hardly business cycle theory at all (see, for example, Summers 1986, 24; Hartley et al. 1997; Solow 1997, 230).

Concerning the empirical side to the object of interest, however, there is more consensus among theorists and business cycle researchers in general. Even though empirical research on business cycles makes it obvious that each cycle is characterized by a certain historical uniqueness, the so called "stylized facts" summarize the observation that there are nonetheless a number of regularities which can be identified when comparing different cycles. "Stylized facts", according to Kaldor (1957), who had first compiled a list of this kind for growth processes and coined the term, are generalized empirical observations. The particular impulses and propagators of business cycles may be varying, at least with respect to their degree, from cycle to cycle, but there are still notable similarities. Business cycles consist of movements in different variables, which do not only reappear frequently, but are also correlated serially and across variables (see Zarnowitz 1992, 22) - a number of regularities which theories should attempt to reproduce. These summarizing observations go back to the reference graphs in Burns and Mitchell (1946, Ch. 5) and Mitchell (1951, Ch. 4 and Ch. 10 III), who had aimed to conclude their extensive work in a few structured, key regularities.

Following Lucas (1977, 9), Zarnowitz (1992, 23 ff.) and Ryan (2002, 100 ff.), eight "stylized facts" can be summarized to describe movements in economic variables in relation to movements in aggregate output (i.e. procyclical changes imply movements in the same direction as output). ${ }^{1}$ In par-

\footnotetext{
${ }^{1}$ The full list of the stylized facts, as presented by these authors, is as follows: (1) High
} 
ticular, they include the observation that prices generally move pro-cyclically, that is, they have a tendency to rise during an upswing and fall during a downswing. Furthermore, one of the most eminent observations on "real" economic variables is that unemployment moves anti-cyclically: it increases during a downswing, but usually decreases during an upswing. These two stylized facts will be primarily considered in what follows. The paper thus analyses both an eminent "monetary" and a "real" observation.

Additionally, the duration of cycles can also be considered to be a "stylized fact", although it is usually not explicitly listed among these items. Major empirical studies document an average cycle duration of often around five and up until around eight and sometimes ten years, at least for the decades after World War II in most industrialized countries. ${ }^{2}$ Among the stylized facts, those relating to "real" variables are especially noteworthy, because those are usually the most clearly documented and least contested in empirical and theoretical disputes.

Even though many studies of the business cycle focus on developments in the U.S., there are also analyses of similar movements in other countries. Some of the early works already documented data for several countries (i.e. the U.S., France, the United Kingdom and Germany in Burns and Mitchell 1946), and there is comparable research for other major industrialized countries as well, such as Kromphardt (1993, 10 ff.) and Maußner (1994, 14 ff.) for Germany, Fiorito and Kollintzas (1994) for a study of the G7 economies, and Agresti and Mojon (2001) for the Euro area (where the authors even emphasise the similarity to observations of the U.S. economy). Still, it should be pointed out, and the subsequent discussion in Section 3 will corroborate this statement, that the generalized observations which the stylized facts de-

coherence of output movements: production across virtually all sectors of the economy moves in the same direction, often in similar magnitudes. (2) Cycles of durable goods (especially including machine equipment) are more pronounced. (3) Time series of prices and production in the primary sector (agriculture) have below average conformity. (4) Profits are characterized by high conformity and a larger amplitude compared with other time series. (5) Prices generally move pro-cyclically (see the following discussion on the dispute regarding this observation). (6) Short-term interest rates are pro-cyclical, longterm interest rates less so. (7) Monetary aggregates and their velocity move pro-cyclically. (8) Unemployment develops anti-cyclically.

Especially the movement of investment over a cycle has been among the first empirically documented regularities (see Kuznets 1933). As regards the movement of profits, the other side of the same coin is an observation already due to Mitchell (1913) that during the upswing of a business cycle, wages rise more slowly than national income on average, and fall more slowly during a downswing. Accordingly, the profit share in national income rises during an upswing, and falls in the downswing (see Sherman 2001, 90 f.).

${ }^{2}$ This is clearly documented in data from the NBER. Further see Zarnowitz (1992, 22 f.), Bergman et al. (1998) and Romer (2008), also Burns and Mitchell (1946). 
scribe are most apt to describe U.S. developments - but even then, primarily a description of trends and general relations, not detailed illustrations.

As regards the method of analysis, not its international scope, there is an important shift in technique which was introduced especially in context of the advent of RBC theory. This is especially important concerning the question of linking the stylized facts to particular numbers, i.e. any form of quantitative (or quantifiable) measure. Whereas earlier contributions often worked with reference graphs and pointed out co-movements between variables, whether pro- or anti-cyclical, on a rather qualitative level, RBC research in particular has taken this approach a step further. A frequent method is to compare correlations between time series detrended with a filter (usually Hodrick-Prescott) for different lag coefficients, in order to investigate both the strength and most distinct timing of relations. As a byproduct of such studies, it is evident that there are not only different correlation coefficients for various lag coefficients, but also between countries. As of yet, however, it has not been a primary topic in the literature to discuss and attempt to explain international differences when they become apparent, both statistically and theoretically.

Furthermore, even after taking account of the caveats just mentioned, it should be noted that the list of stylized facts as reproduced in Footnote 1 above is not universally accepted. Indeed, the present paper is not the first to call their generality into question. In some cases, even the direction or essence of the stylized facts is not uncontroversial - even concerning one of the observations analysed in what follows. Since the advent and in the context of RBC theory, it has frequently been argued and empirically documented ${ }^{3}$ that prices do not move pro-, but anti-cyclically instead, i.e. that they would actually decline in a boom, and rise during a recession. Going even farther than this criticism of one particular item, other studies such as one based on 11 OECD countries by Woitek (1997) reject the usual list, as reproduced above, altogether, and suggest a different set of stylized facts. In general, it may be concluded from the literature that the stylized facts on real economic relations (especially points 2 and 8) are far more uncontroversial, at least in their general direction, than observations concerning monetary variables.

To conclude this discussion on the theoretical background and related literature, it can be summarized that the stylized facts of the business cycle are frequently accepted generalized descriptions, both in the theoretical and empirical literature, that they may be similarly applied in many respects to observations in most industrialized countries, but that they are far from being

\footnotetext{
${ }^{3}$ See Kydland and Prescott (1990) for the original presentation of this thesis, and also Ryan (2002, 100 ff.).
} 
a uniform description of actual movements and co-movements in economic variables among different countries. Additionally, concerning the question of providing possible explanations of said differences, it is hard to find a comprehensive and systematic analysis in the literature. This, therefore, is where the present paper will provide its contribution: It will summarize differences for some of the most prominent stylized facts, and, following the idea employed by Calmfors et al. (1988) in a related context, investigate whether these can be statistically - and, following that step of the analysis, theoretically - explained by reference to the economies' institutional variables. The details and results of the analysis are laid out in what follows.

\section{Methods, Data and Results}

This section will lay out the method used in the following to measure and estimate stylized facts of the business cycle, document the data used to do so, and finally present results on the measured and estimated relations as well as on their degree of dependence on several sets of institutional variables. A particular focus will be on country-specific differences, and whether and how they can be statistically explained by the institutional variables used here. In the extent performed within this paper, this constitutes a novel contribution to the literature. The next section will then provide a theoretical discussion of the empirical results.

\subsection{Capturing business cycles}

The "stylized facts" as they were summarized and presented in the previous section are verbal descriptions. In Order to statistically assess these generalized observations, especially whether or not there are differences between countries, the descriptions need to be operationalised first. It is hardly possible to do full justice to all eight "stylized facts" within just one paper, so the following analysis will focus on three relations, capturing two stylized facts, in particular. As will be seen, however, the method employed is perfectly compatible with the other observations and can be readily applied to these as well.

The first relation to be analysed is not a particular "stylized fact", but one of the most eminent macroeconomic relations, especially in the context of business cycle research: the Phillips curve. Including a Phillips curve in the analysis is also a direct tribute to the work of Calmfors et al. (1988), whose work on the relation between bargaining power and real wage changes has inspired this paper's second research question. It is also the relation between 
the two variables captured by the "stylized facts" which will be considered with equations (2) and (3) respectively.

Therefore, equation (1) measures parameters for country-specific Phillips curves, applying the usual method of changes in the inflation rate as the price variable:

$$
\Delta i n f_{t}=\alpha_{0}+\alpha_{1} \Delta u n_{t}+u_{t}
$$

Where $\Delta i n f_{t}$ is a stationary change of inflation, $\Delta u n_{t}$ is a stationary change of the unemployment rate, $\alpha$ s are coefficients and $u_{t}$ is an error term. The stationarity of the first differences is tested with the GLS version of the Augmented Dickey Fuller test (further DFGLS test), which performs better on the small samples. In addition, the residuals are tested on autocorrelation and heteroscedasticity with the Breusch-Godfrey and Breusch-Pagan/CookWeisberg tests.

The second equation and corresponding model now captures a particular "stylized fact" more directly. Equation (2) is applied to measure the correlation between unemployment and GDP over the business cycle, explaining trend deviations in unemployment by trend deviations in GDP, applying the usual methods (see below). In addition to capturing a "stylized fact", the relation measured by equation (2) may also be regarded as a particular formalization of Okun's Law (Okun 1962).

As opposed to what can sometimes be found in more comprehensive studies of the "stylized facts" only, the following analysis will not take any lags into account and focus only on the correlation in the same period. From the point of view of economic theory, this may seem an over-simplification, for it implies that unemployment reacts to output changes right away; however, from the econometric perspective, it allows to minimize autocorrelation issues. Furthermore, since annual data will be used, this caveat from economic theory should weigh less severe.

The equation capturing the relation between unemployment and GDP thus reads:

$$
\left(u n_{t}-u n_{t}^{*}\right)=\beta_{0}+\beta_{1}\left(g d p_{t}-g d p_{t}^{*}\right)+u_{t}
$$

Where $u n_{t}-u n_{t}^{*}$ is a stationary deviation from the trend of the unemployment rate, $g d p_{t}-g d p_{t}^{*}$ is a stationary deviation from a GDP per capita trend, $\beta \mathrm{s}$ are coefficients and $u_{t}$ is an error term. To obtain the cyclical fluctuation, the Hodrick-Prescott filter (HP filter) is applied as in Hodrick and Prescott (1997). For the $\lambda$ parameter, 6.25 is chosen as in Ravn and Uhlig $(2002,374)$. The stationarity of the cyclical fluctuations is ensured with the DFGLS test and the residuals are tested for autocorrelation and heteroscedasticity. 
The third model to be considered picks up number a central monetary "stylized fact". For this relation between output and prices, captured in equation (3), it will be particularly interesting to not just look at differences between countries, but also between this model and the second in particular, since, as pointed out in Section 2, there is quite some controversy about the question of whether or not prices move pro-cyclically. Applying the same methods and logic as for the previous model, equation (3) reads:

$$
\left(i n f_{t}-i n f_{t}^{*}\right)=\gamma_{0}+\gamma_{1}\left(g d p_{t}-g d p_{t}^{*}\right)+u_{t}
$$

Where $i n f_{t}-i n f_{t}^{*}$ is a stationary deviation from the trend of the inflation rate, $g d p_{t}-g d p_{t}^{*}$ is a stationary deviation from a GDP per capita trend, $\gamma \mathrm{s}$ are coefficients and $u_{t}$ is an error term. The cyclical fluctuations are obtained in a similar manner as in model (2) and the same tests are carried out.

Two important methodological issues related to the estimation of models (1), (2) and (3) are heteroscedasticity and serial correlation. The first issue is tackled by testing for heteroscedasticity according to Breusch and Pagan (1979) and applying robust standard errors as in White (1980) where it is needed. ${ }^{4}$ In order to deal with autocorrelation, the test as in Breusch (1978) and Godfrey (1978) is applied first. After obtaining the test results, the autocorrelation consistent errors as in Newey and West (1987) are applied subsequently. ${ }^{5}$

Furthermore, as pointed out in Section 2, there is an additional generalized empirical observation which is not usually found explicitly among the lists of "stylized facts", but may still be regarded as one: the duration of business cycles.

In order to estimate this variable, two well-established methods of spectral analysis are applied to the stationary cyclical fluctuations of the real GDP per capita series. Fast Fourier Transform (further FFT) algorithm allows the use of Discrete Fourier Transform (DFT) and extraction of a dominant frequency of the stationary annual data. The DFT formula is displayed below:

$$
X_{k}=\sum_{n=0}^{N-1} x_{n} e^{-i 2 \frac{n}{N}}
$$

In order to validate the estimations of the duration of business cycles with the first method, a second, more advanced tool is required. The Multiple

\footnotetext{
${ }^{4}$ First we test for heteroscedasticity and apply the robust errors only if the tests suggests heteroscedasticity on the $5 \%$ level. Robust errors do not alter the coefficients of interest; however, the significance level may change.

${ }^{5} \mathrm{~A} 5 \%$ benchmark for the autocorrelation test is used and the autocorrelation consistent errors are applied only where necessary. As in the case of robust errors, the coefficients remain the same.
} 
Signal Classification (further MUSIC) based on Schmidt (1986) returns a pseudo-spectrum which allows an approximation of the dominant frequency. The estimation of the pseudo-spectrum includes eigenvalues and weights. The number of dimensions is set to two ${ }^{6}$ due to the assumption that there are high and low frequency cycles present in the data.

$$
\hat{P}_{M U}\left(e^{j \omega}\right)=\frac{1}{\sum_{i=p+1}^{M}\left|e^{H} v_{i}\right|^{2}}
$$

The main strategy of this paper is to estimate coefficients of interest $\alpha_{1}, \beta_{1}, \gamma_{1}$ and the dominant frequency. After the estimation, the relation of the latter parameters to the institutional variables is analyzed with nonparametric methods (see Spearman, 1987; Kendall, 1938). ${ }^{7}$

\subsection{Data}

The data for estimation of the equations and the dominant frequency is taken from OECD.Stat and additional data for institutional comparison is taken from the DICE database, provided by CESifo. The time frames for the empirical data is from 1960 to 2012. The countries under consideration ${ }^{8}$ are: Australia, Austria, Belgium, Canada, Denmark, Finland, France, Germany, Iceland, Ireland, Italy, Japan, South Korea, Luxembourg, the Netherlands, New Zealand, Norway, Sweden, Switzerland, Turkey, the UK and the USA. The empirical proxies for variables from models (1), (2) and (3) are: consumer price index inflation (CPI), unemployment rate and real gross domestic product per capita (GDP per capita).

Empirical proxies for institutional features of the given countries include eight variables. The coefficient of variation (further CV) provides a measure of the volatility of long and short run real interest rates, taken from the OECD.Stat database for the period from 1960 to 2012. These are taken as proxy measures for monetary policy. Whereas for interest rates the method of aggregation is the $\mathrm{CV}$, for other variables averaging was used. The data for

\footnotetext{
${ }^{6}$ Setting signal dimensions higher than two does not significantly shift the estimated value of the dominant frequency and merely creates additional humps in the pseudospectrum up to the fourth signal dimension.

${ }^{7}$ One has to note that parametric methods are optimal if the data are normally distributed. Otherwise, one should consider non-parametric estimates. In this paper, normality is checked for with the test as in Shapiro and Wilk (1965). According to the test, the institutional proxies are not normally distributed and therefore non-parametric methods are appropriate.

${ }^{8}$ The countries were selected according to the availability of the data bearing in mind the time frames.
} 
the trade as \% of GDP indicator is also taken from OECD.Stat for the same time period. All other proxy variables are taken from the CESifo database and pertain to the labour market: The benefit replacement rate is originally due to Nickell (2006) and covers the period from 1960 to 2003. The data on public expenditures on out-of-work income maintenance and support as a \% of $\mathrm{GDP}^{9}$ is taken from the DICE ${ }^{10}$ and covers the time period from 1985 to 2010. The collective bargaining data ${ }^{11}$ was taken from Bassani (2006) and is related to the period from 1970 to 2003 . The data on labour union coverage is taken from Ochel (2001) and covers the time period from 1960 to 1994. The data on union density originates from the DICE database ${ }^{12}$ and covers the period from 1960 to 2011.

\section{$3.3 \quad$ Results}

First, the coefficients of interest, $\alpha_{1}, \beta_{1}, \gamma_{1}$ and dominant frequencies are estimated.

Tables 1-3 below report values and correlation coefficients of the coefficients and t-values of the empirical models. The coefficient displays the magnitude whereas the T-statistics show the significance of the effect. It should be acknowledged that the significance is subject to the type of errors, and therefore, Breusch-Godfrey and Breusch-Pagan/Cook-Weisberg tests on autocorrelation and heteroscedasticity are performed. Newey or robust standard errors are applied only where it is required by the $5 \%$ test benchmark. The type of errors is reported in the tables.

In Table 1, the coefficients and significance of the relation between changes of inflation and changes of unemployment from the first model (1) is documented. From this table, several interesting findings can be pointed out. Firstly, most of the coefficients are negative except for Denmark, South Korea and Turkey. One has to note that most of the coefficients are significant, except for the above-mentioned countries and Belgium, Iceland and the Netherlands. Secondly, the CV of the short term interest rates has a significant and negative correlation with both, the coefficient and the significance. This literally means that higher variance of the short term interest rates is associated with a steeper slope of the relation between changes of inflation and changes of unemployment and with a higher significance of this relation. The latter

\footnotetext{
${ }^{9}$ For simplicity, this proxy will be referred to as "benefits".

${ }^{10}$ The data in the DICE database were derived from the OECD Online Employment Database.

${ }^{11}$ The data are also based on the OECD Employment Outlook 2004.

${ }^{12}$ This database is partly based on the OECD data (particularly on the Trade union density, OECD Employment and Labour Market Statistics).
} 
fact is particularly interesting: high variance is associated with a better fit of model (1). Secondly, the benefit replacement rate has a significant and positive correlation with both, coefficient and significance from model (1). To paraphrase, high replacement rate is associated with a flatter slope of the relation between changes of inflation and changes of unemployment and lower significance of this relation. The correlation of the out of work support benefits with the coefficient on model (1) echoes this finding; however, the significance is not correlated: higher out of work support is associated with a flatter slope. Trade as a \% of GDP has a significant positive correlation only in case of the Spearman rank correlation, whereas Kendall's tau does not confirm the effect.

The results from the next model (2), which estimates the relation between the cyclical fluctuations of unemployment and cyclical fluctuations of output, are reported in Table 2. All of the coefficients have a negative sign and most are significant except for Italy and Turkey. The variance of the interest rates did not have significant correlation neither with the coefficient nor with significance. However, the proxies for the labour market institutions did: the out of work support benefits had a positive correlation with the coefficient. Kendall's tau was significant for correlation of the out of work benefits with the coefficient as well. This would mean that the higher the out of work support is, the steeper the slope of the relation between the cyclical fluctuations of unemployment and cyclical fluctuations of output is. Other variables did not demonstrate any significant correlation, except for the bargaining and labour union coverage which had positive correlation with the significance values; however, only on a $10 \%$ level. Higher bargaining and union coverage is associated with better fit of the relation between the cyclical fluctuations of unemployment and cyclical fluctuations of output.

The last model (3) estimates the relation between the cyclical fluctuation of inflation and cyclical fluctuation of output. Whereas the previous models yielded similar signs for the coefficients, Table 3 reports heterogeneous results. Significant and positive relation between cyclical fluctuation of output and inflation can be found for Belgium, Canada, Finland, France, Germany, Italy, Sweden and Switzerland, whereas significant negative coefficients can be found for Korea, Turkey and the UK. In the US the coefficient is positive; however, not significant. The only substantial correlation to be found is the positive correlation of the $\mathrm{CV}$ of the short term interest rates with the coefficient and a positive correlation of the labour union coverage. However, this correlation is significant only on the $11 \%$ value, outside the conventional levels. At this point, it can be stated that high $\mathrm{CV}$ of the short term interest rates and high union coverage is associated with higher coefficients of the relation between the cyclical fluctuation of inflation and cyclical fluctuation 
of output.

The duration of the cycles is displayed in Figure 1 and Table 4. The values in Table 4 variate from 4.63 years for New Zealand to 6.84 for Italy with the weighted MUSIC method and from 4.02 years for New Zealand to 8.1 for Sweden with the FFT method. Table 4 reports correlation results with the duration of the cycles estimated by both, FFT and the weighted MUSIC methods for due diligence. From the table it follows that the labour market institutions, or to be precise, the replacement ratio, are related to the duration of the cycles: a high replacement rate is associated with shorter cycles, whereas a lower rate is associated with longer cycles. The latter effect is valid only for the FFT estimates. Another interesting effect which was captured is the significant and negative correlation between the $\mathrm{CV}$ of the long term interest rates and the duration of cycles: higher variance of the long term rates is associated with shorter cycles. However, we have discovered a significant and positive correlation between the duration and the variance coefficient of the short term interest rates: higher variance is associated with longer cycles.

Figure 1: Duration of business cycles

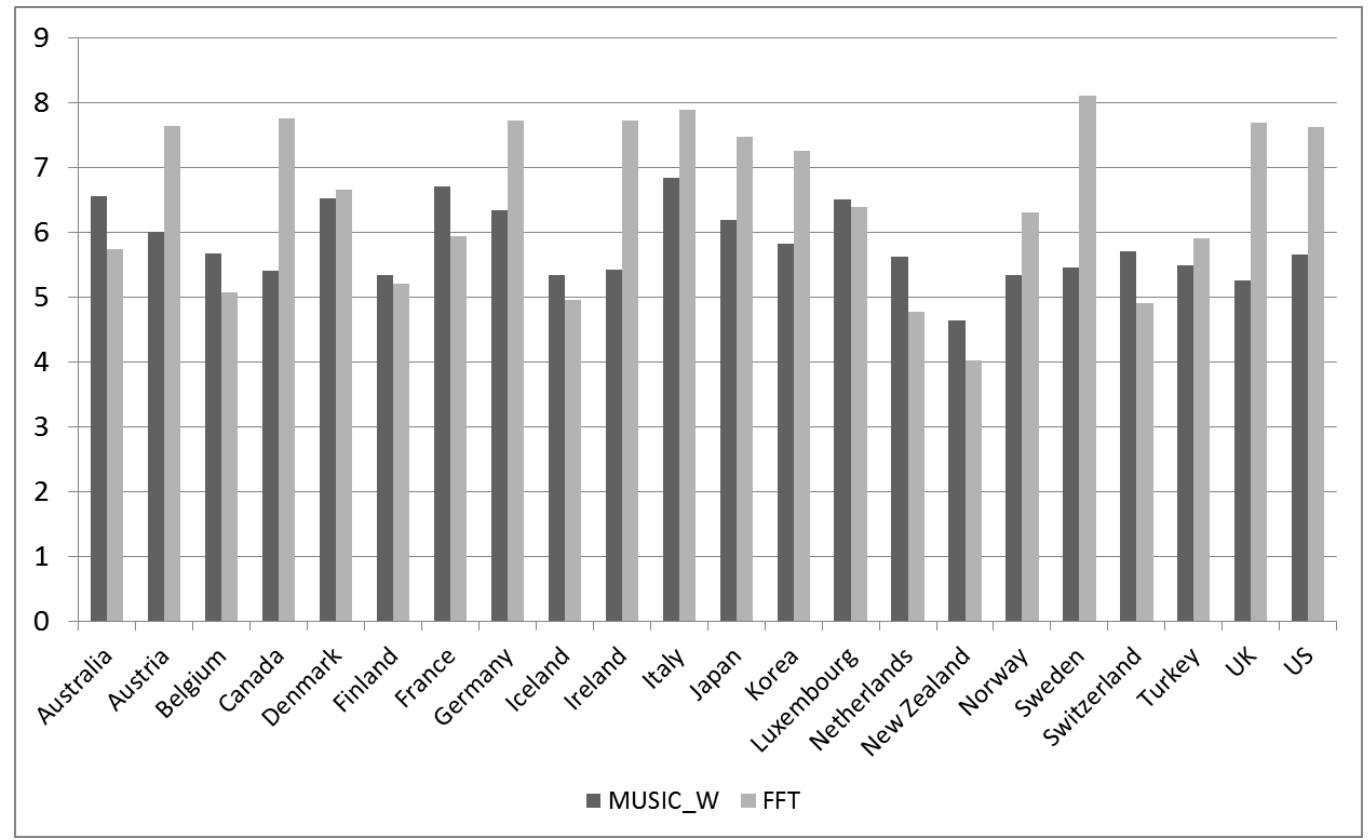

Source: OECD. Based on the HP filtered data of real GDP per capita. 


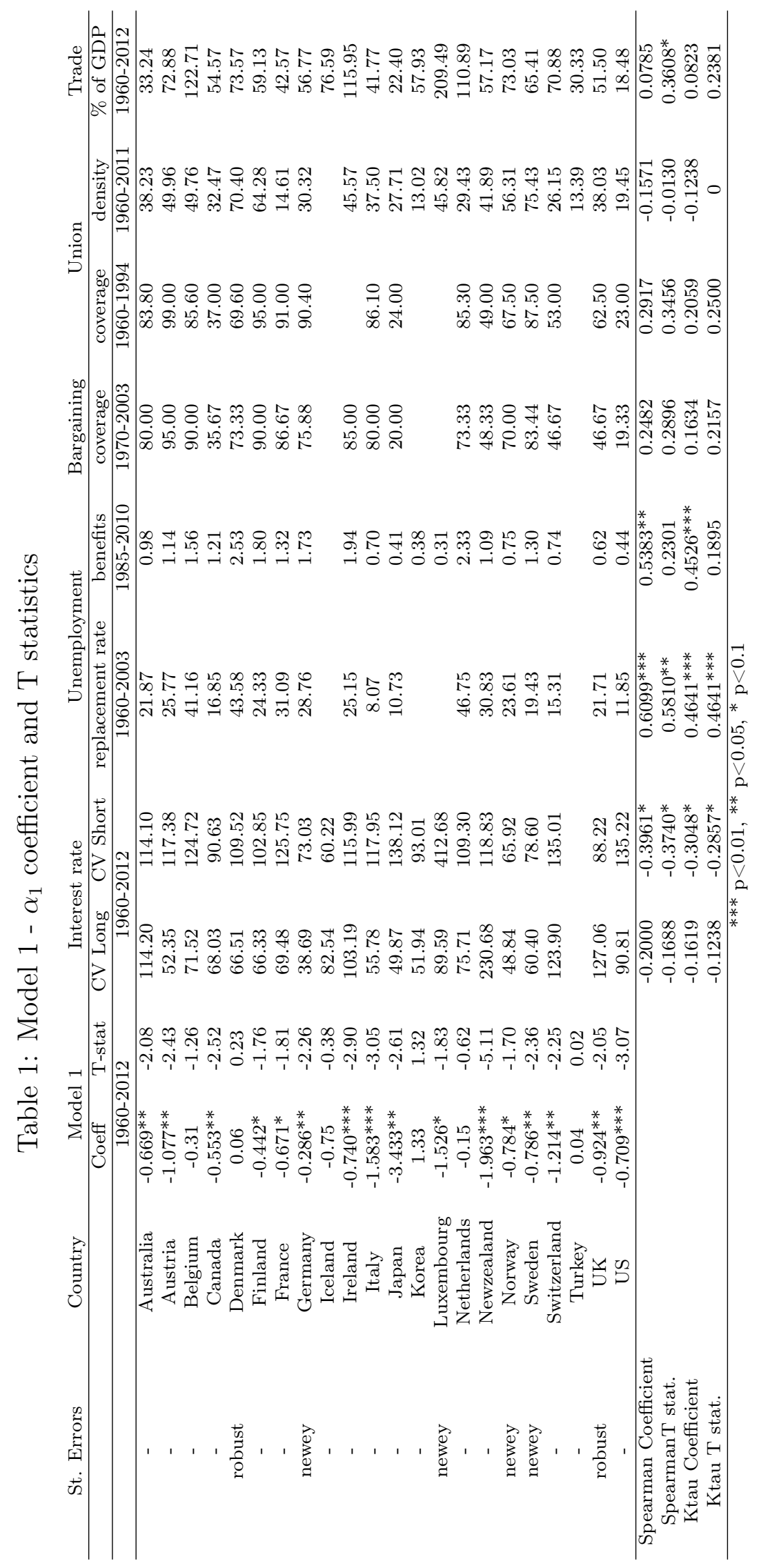




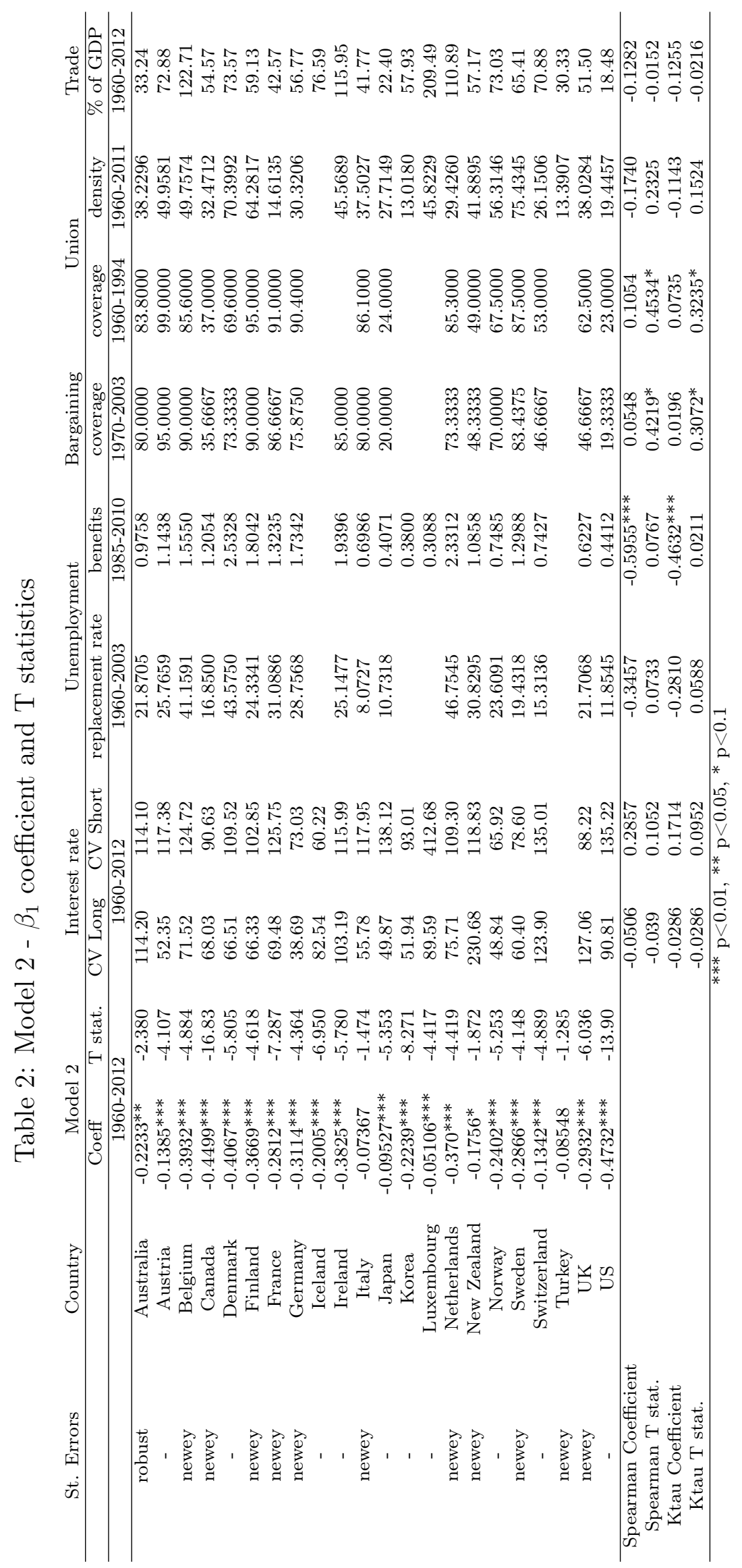




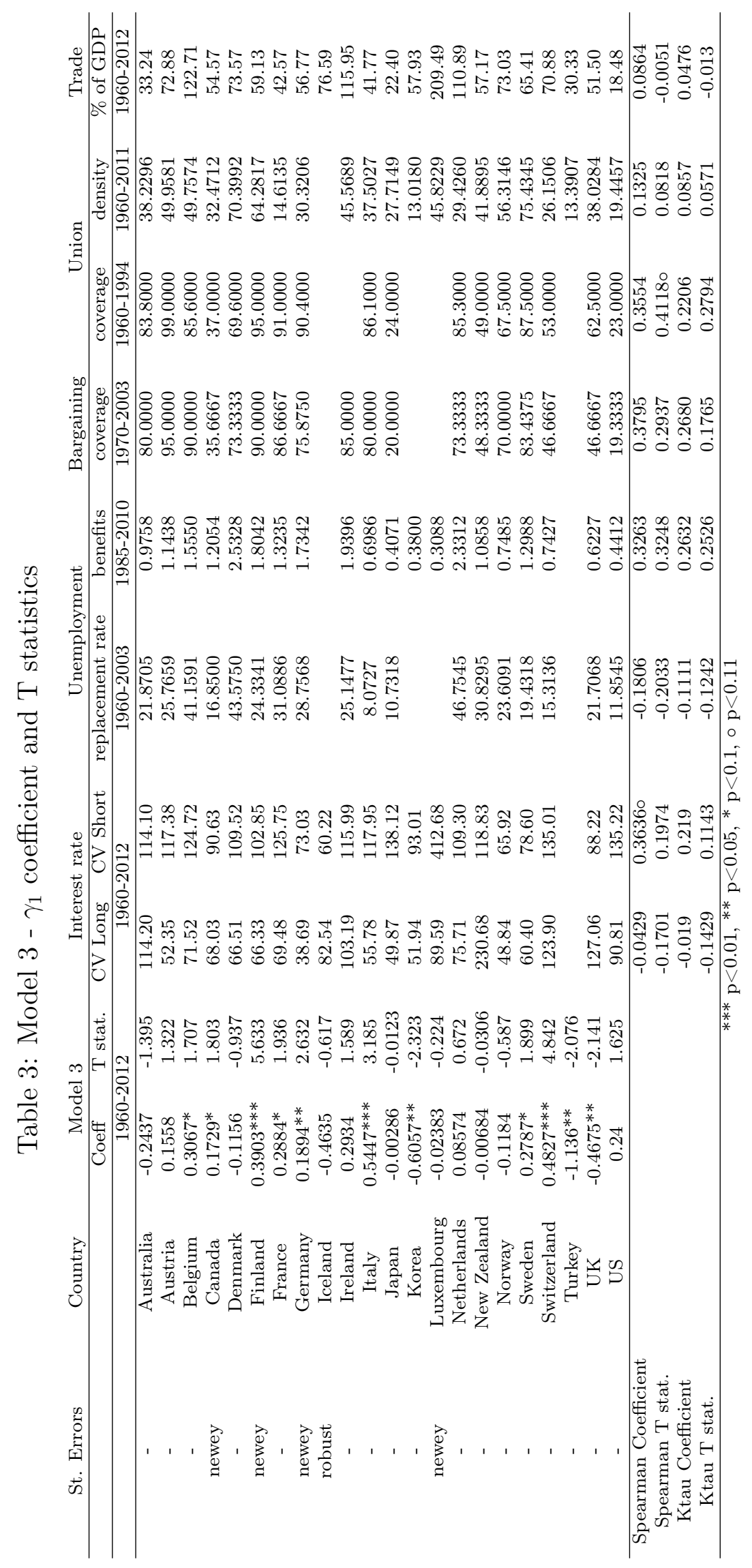




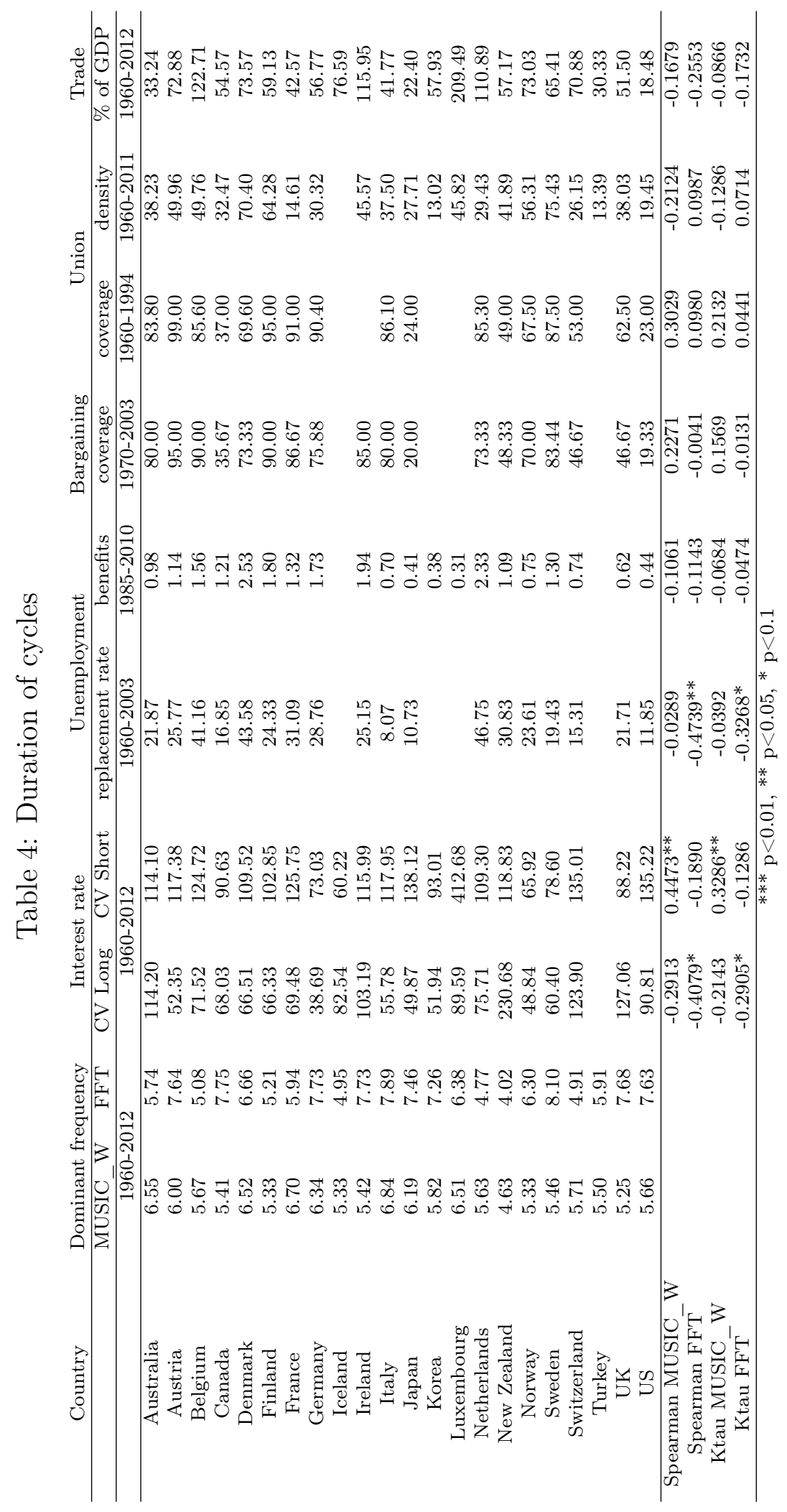




\section{Interpretation and discussion}

The foregoing analysis has provided some notable results, and it is worthwhile to discuss these empirical findings from a theoretical perspective as well. Generally, it may be concluded that the prevalence of the stylized facts concerning real economic variables, of which the unemployment-output relation was tested in this paper could be confirmed for the OECD members, although notable differences exist between countries, mostly concerning the strengths of the relations. The existence of the nominal stylized fact which was considered - the pro-cyclicality of prices, in the form of a correlation between inflation and GDP per capita - could not be unanimously confirmed, thus further adding to the dispute over this observation in particular, which, as already pointed out in Section 2, has been questioned to the point of switching the algebraic sign of the relation in the RBC literature.

As concerns model (1), what was measured here was really an altered Phillips curve relation by the now standard method of using first order differences: in equation (1), changes in the inflation rate were correlated with changes in the unemployment rate. The coefficient $\alpha_{1}$ thus becomes a measure of the slope of this Phillips curve: an absolutely large coefficient for model (1) indicates that changes in the unemployment rate have a strong impact on the inflation rate, i.e., the larger (in absolute terms) the coefficient, the closer the curve gets to a vertical. Two of the institutional variables were strongly and significantly correlated throughout: the CV of short term interest rates (negative), and the replacement rate (positive). The former implies that a more volatile interest rate increases the negative slope of the Phillips curve (in absolute terms). This is a puzzling finding. Since a steep slope on the Phillips curve may be seen as a proxy for a relatively stable "natural" rate of unemployment, with inflation only causing short term deviations at best, the result would imply that the economy is more likely to stay closer to this unemployment level if short term interest rates fluctuate more strongly. However, if the story is turned around, an explanation of the kind that the fluctuations in the short term interest rate are exactly what keeps this relation in check - and the economy close to the particular unemployment level - may be more compelling. On the other hand, it may be the case that the high $\mathrm{CV}$ on short term interest rates is simply a consequence of monetary policy having to react more strongly on fluctuations in an economy in which inflation (or deflation) threatens to run away more rapidly with changes in unemployment. Thereby, this institutional variable would rather be the result of other institutional factors than an explanatory variable itself. In general though, the interpretation of these results is subject to debate and invites further research. 
It is easier to interpret the second strong and highly significant correlation observed in model (1), namely between replacement rates (and also the benefits measure) and the coefficient $\alpha_{1}$. The relation is positive, which means that higher benefits imply a flatter Phillips curve. In other words, in an economy with high replacement rates, a given change in the unemployment rate likely translates into a lower change in the inflation rate than it would in another economy with lower unemployment benefits. This result is more intuitively appealing: In general, higher benefits mean that unemployment is less of a threat to individuals, so that they are less likely to drastically decrease their wage bargain expectations (which in simple models ultimately feature into the inflation rate) when hit by a spell of unemployment. On the other hand, this explanation does not account for the fact that the single coefficient estimated here implies that the slope would also be low to the left of a hypothetical "natural" rate of unemployment. In contrast, it might be argued that workers who can rely on large benefits in case of unemployment are more likely to perceive themselves to be in a very strong bargaining position in periods of high employment in general. This would, however, imply a non-linear model, which the linear regression approach used here does not capture. The general story to be told for this result is quite convincing though, especially because it connects well to observations for the next model.

In model (2), which relates changes in the unemployment rate to deviations of GDP per capita relative to its trend level, a correlation in line with the stylized fact was found universally among all countries: The coefficient was highly significant (with the exceptions of Turkey, Italy, and, to a lesser degree, New Zealand) and negative for all countries, which confirms that the unemployment rate decreases if GDP per capita grows above trend. However, the actual values for the coefficients were very different among the countries: in Italy, for example, GDP per capita growth at 1 percentage point above its trend level would reduce the unemployment rate by less than 0.1 percentage points, whereas the same growth difference reduces the unemployment rate by almost 0.5 percentage points in the U.S. The stylized fact is therefore confirmed for all OECD countries, but its quantitative level varies widely among countries, and the precise reaction of unemployment is therefore far from generalizable.

In this context, it appears straightforward to appeal to Okun's Law (see Okun 1962 for an original illustration), which relates changes in unemployment to GDP growth, and $\beta_{2}$ may therefore be referred to as the Okun coefficient. The discussion on explanations for Okun's Law revolves mainly around labour market institutions which, for example when comparing the U.S. and Europe, may make "hire-n-fire"-strategies more feasible on one side 
of the Atlantic as opposed to the other, thus causing a stronger reaction of unemployment to GDP growth: In a boom, firms which know that they will be able to dismiss workers once the boom ends more easily will be less reluctant to hire new employees right away, whereas, on the other hand, tight labour market regulations become especially visible in a recession where firms might not be able to decrease employment as much as they would desire due to legislatory constraints. Therefore, an absolutely higher negative coefficient is to be expected for the U.S. than, on the other hand, Italy - as documented above. However, this simple picture cannot be confirmed in general, with some continental European countries having coefficients close to the one estimated for the U.S., and often higher than the U.K. value. The statistical analysis confirms this, with hardly any significant correlations between the labour market institutions and the coefficients for the unemploymentGDP-relations. The only strongly significant and uniform result is found for correlations between benefits and the estimated coefficient $\beta_{2}$.

In general, however, it is evident from the results documented in Table 2 that the institutional variables taken into account here are insufficient to explain the differences between countries. Okun's Law and the story often told behind it offers an appealing rationale, but it is not exactly in line with the numbers as documented. This calls for further research which takes additional institutional variables into account, even though the present study already includes mostly labour market proxy variables.

Whereas model (2) pointed out the validity, but large quantitative differences in what may very well be the most important "real" stylized fact, i.e. the output-unemployment-relation, the results for model (3) as documented in Table 3 clearly confirm the skepticism regarding the monetary stylized facts, which was already articulated in Section 2. The coefficients $\gamma_{1}$ documented in Table 3 are not only very different in absolute value and in their degree of significance, but additionally, there are both countries in which the sign is positive, and others where it is negative. Of the 22 countries observed, 10 display negative signs. Significant values are observed in both directions. This means that there are some countries, such as the U.K., where inflation decreases during a boom, whereas in others, such as France or Germany, it increases. The first observation is in line with the RBC story, the second with the majority of previous business cycle theories and empirical observations. Interestingly, the coefficient for the U.S. is positive, but it is not significant. This may contribute to an explanation of why both pro- and anti-cyclical movements of prices have been observed for the U.S. Given these observations and results, the stylized fact that prices move in a certain pattern along the business cycle - be it pro- or anti-cyclically - may be regarded as an artifact, at least when comparing different countries (even fairly similar ones 
such as the OECD members, or even within major European economies) on the international level.

Even if the stylized fact of (pro-/anti-)cyclical price movements is thus rejected, it is still worthwhile to investigate the origins of country-specific difference - in fact, this exercise might be even more promising with the larger differences observed between countries in this model. However, none of the institutional variables taken into account here correlate significantly with the estimated coefficients $\gamma_{1}$. The difference between countries in their outputinflation-relations are thus evident, but they cannot be explained sufficiently by the institutional variables used here.

Finally, the empirical analysis in this paper has also estimated the length of cycles in the different countries observed. The results are generally in line with the numbers provided in the literature. Correlations of this number with the institutional variables were documented in Table 4 . Once more, the estimated correlations allow for only a careful interpretation at best. This is most evident from the CVs of the short- and long-term interest rates: the correlation coefficients with the cycle durations have different signs, and are even significant for the two different methods. Concerning the labour market and trade variable, only the replacement rate provides a negative correlation with the FFT results: A higher replacement rate implies a shorter business cycle. Since the coefficient for MUSIC is much lower and not even significant, it is questionable whether a theoretical explanation needs to be attempted here at all. Indeed, it should be noted that different spectral analysis methods not only provided different lengths of the cycles, but also vastly different rank orders between countries, if ordered by business cycle length. The results presented here are the most robust, but in general, the results from the spectral analysis have to be taken with a lot of caution, especially in context of a method such as here where rank correlation coefficients are applied the correlation results may easily be a statistical artifact and consequence of the particular method chosen for spectral analysis. Since no uniform correlation results with different methods of spectral analysis could be observed here, no further theoretical explanation of differences among countries will be attempted. It should just be noted that in general, the lengths of business cycles estimated here (between four and eight years) are in line with previous research.

Overall, the results presented and discussed here provide strong evidence against the universality of a central monetary "stylized fact" of business cycles, and point out notable country-specific differences in crucial macroeconomic relations. The institutional explanation of these results has to be met with many caveats due to the lack of uniform results pointing in the same direction. Whereas the results clearly do not contradict the thesis 
that institutional factors may be an important explanatory variable behind macroeconomic fluctuations over the course of a business cycle, they do not strongly confirm it either. Further research is therefore necessary to investigate whether the sometimes ambiguous results are due to problems connected to the methods or data (in particular the institutional variables) employed here, or whether indeed other institutional variables than those observed here, such as e.g. overall levels of state/government activity, central bank independence etc., perform better at explaining the differences between countries.

\section{Summary and conclusion}

The research interest of this paper has been twofold: First of all, to investigate whether or not the so called "stylized facts" of business cycles are general phenomena, or if there are notable differences between economies, even across a set of generally fairly similar countries (i.e. a subset of OECD members). Secondly, picking up these results, the paper included various institutional variables to further probe whether or not observed differences between countries could be explained by institutional factors. It was found that there are notable country-specific differences indeed, and that especially the monetary "stylized fact" regarding the pro-cyclical movement of prices rests on fragile grounds. It was further demonstrated that some of the differences could be explained by the institutional variables included in this study, but that there are clear limitations to the data used still. However, the underlying hypothesis of noteworthy variety in the "stylized facts" and a potential for institutional explanations of these was confirmed and subsequently discussed.

The main empirical findings documented in this paper can be summarized as follows. The stylized facts on business cycles are not universal, at least considering the OECD sample for the period of 1960-2010: the magnitude and direction of interaction between inflation, unemployment and output varies from one country to another; the duration of business cycles varies from four to eight years. Bearing this heterogeneity in mind, an attempt to explain these variations with the help of institutional variables representing monetary policy, labour market institutions and trade as a proxy for an economy's openness was carried out. It was found that the slope of the Phillips curve, $\alpha_{1}$ from model (1), has a strong statistical relation with the coefficient of variation of short term interest rates (negative), and the replacement rate (positive). The Okun coefficient $\beta_{1}$, from model (2), is statistically related to the share of GDP spent on unemployment benefits (negative). The variation in the coefficients of the output-inflation-relations, $\gamma_{1}$ from model (3), can not 
be explained by institutional variables, although a weak positive correlation with the coefficient of variation of the short-term real interest rates was found. The variation in the duration of business cycles is related to replacement rates (negative) and to the coefficients of variation of the short- and long-term interest rates, although the sign of the relation is not uniform.

The results presented in Section 3 and discussed in Section 4 provide an overall impression of differences, but they are far from being everything there could be said about this paper's underlying research questions. Two ways to build on and expand the results naturally connect to what was documented: Firstly, only the length of business cycles as well as three macroeconomic relations were estimated in the empirical study, as opposed to a list of usually eight "stylized facts" which are discussed in the literature. Among those not considered, especially the pro-cyclical movement of durable goods, such as investment in particular, would be a natural candidate for further research with the methods employed here. Secondly, the institutional factors themselves are of course a category which could and should be expanded in future analyses. Clearly, the variables considered in this paper are only a fraction of different measures and proxy variables for institutional variables available. Additional variables, such as better proxies for monetary (or maybe even fiscal) policy etc., should allow for further interesting results - whether or not they find significant correlations. Furthermore, one might even pursue a third expansion of this paper's research, i.e. by testing the models estimated here with different lag structures.

To summarize, this paper has therefore contributed to a potentially rich field of research in both theoretical and empirical economics: The econometric analysis of differences across countries with regard to business cycles, and how these may or may not be linked to the countries' institutional frameworks. 


\section{References}

Agresti, A.-M. and Mojon, B. (2001). Some stylised facts on the euro area business cycle. ECB Working Paper Series, 95.

Bassani, A., D. R. (2006). Employment patterns in OECD countries: Reassessing the role of policies and institutions. OECD Social, Employment and Migration Working Paper No.35.

Bergman, U. M., Bordo, M. D., and Jonung, L. (1998). Historical evidence on business cycles: The international experience. In Fuhrer, J. C. and Schuh, S., editors, Beyond Shocks: What Causes Business Cycles?, volume 42 of Conference Series, pages 65-113. Federal Reserve Bank of Boston, Boston.

Breusch, T. S. (1978). Testing for autocorrelation in dynamic linear models*. Australian Economic Papers, 17(31):334-355.

Breusch, T. S. and Pagan, A. R. (1979). A Simple Test for Heteroscedasticity and Random Coefficient Variation. Econometrica, 47(5):1287-94.

Burns, A. F. and Mitchell, W. C. (1946). Measuring Business Cycles. NBER Book Series Studies in Business Cycles. NBER, New York.

Calmfors, L., Driffill, J., Honkapohja, S., and Giavazzi, F. (1988). Bargaining structure, corporatism and macroeconomic performance. Economic Policy, $3(6): 14-61$.

Fiorito, R. and Kollintzas, T. (1994). Stylized facts of business cycles in the g7 from a real business cycles perspective. European Economic Review, 38(2):235-269.

Godfrey, L. G. (1978). Testing against General Autoregressive and Moving Average Error Models When the Regressors Include Lagged Dependent Variables. Econometrica, 46(6):1293-1301.

Haberler, G. (1946). Prosperity and Depression. A Theoretical Analysis of Cyclical Movements. United Nations, New York, 3. edition.

Hartley, J. E., Hoover, K. D., and Salyer, K. D. (1997). The limits of business cycle research: Assessing the real business cycle model. Oxford Review of Economic Policy, 13(3):34-54.

Hodrick, R. J. and Prescott, E. C. (1997). Postwar U.S. Business Cycles: An Empirical Investigation. Journal of Money, Credit and Banking, 29(1):116. 
Kaldor, N. (1957). A model of economic growth. The Economic Journal, 67(268):591-624.

Kendall, M. G. (1938). A New Measure of Rank Correlation. Biometrika, 30(1/2):81-93.

Kromphardt, J. (1993). Wachstum und Konjunktur. Grundlagen der Erklärung und Steuerung des Wachstumsprozesses, volume 26 of Grundriss der Sozialwissenschaft. Vandenhoeck \& Ruprecht, Göttingen, 3. edition.

Kuznets, S. (1933). Seasonal Variations in Industry and Trade. NBER, New York.

Kydland, F. E. and Prescott, E. C. (1990). Business cycles: real facts and a monetary myth. Federal Reserve Bank of Minneapolis Quarterly Review, 14(Spring):3-18.

Lucas, R. E. (1977). Understanding business cycles. In Brunner, K. and Meltzer, A., editors, Stabilization of the domestic and international economy, pages 7-29. North-Holland, Amsterdam.

Maußner, A. (1994). Konjunkturtheorie. Springer, Berlin.

Mitchell, W. C. (1913). Business Cycles. University of California Press, Berkeley.

Mitchell, W. C. (1951). What Happens During Business Cycles: A Progress Report. NBER Book Series Studies in Business Cycles. NBER, New York.

Newey, W. K. and West, K. D. (1987). A Simple, Positive Semi-definite, Heteroskedasticity and Autocorrelation Consistent Covariance Matrix. Econometrica, 55(3):703-08.

Nickell, W. (2006). The CEP-OECD institutions data set (1960-2004). CEP Discussion Paper No 759.

Ochel, W. (2001). Collective bargaining coverage in the OECD from the 1960s to the 1990s. CESifo Forum, 2 (4):62-65.

Okun, A. M. (1962). Potential GNP: Its Measurement and Significance. In American Statistical Association, editor, Proceedings of the Business and Economic Statistics Section.

Ravn, M. O. and Uhlig, H. (2002). On adjusting the Hodrick-Prescott filter for the frequency of observations. The Review of Economics and Statistics, 84(2):371-375. 
Romer, C. D. (2008). Business cycles. In Henderson, D. R., editor, The Concise Encyclopedia of Economics. Library of Economics and Liberty, Indianopolis, 2. edition.

Ryan, C. (2002). Business cycles: Stylized facts. In Snowdon, B. and Vane, H. R., editors, An Encyclopedia of Macroeconomics, pages 97-104. Edward Elgar, Cheltenham.

Schmidt, R. O. (1986). Multiple emitter location and signal parameter estimation. IEEE Transactions on Antennas and Propagation, vol. AP-34, March 1986:pp. 276-280.

Shapiro, S. S. and Wilk, M. B. (1965). An analysis of variance test for normality (complete samples). Biometrika, 3(52).

Sherman, H. (2001). The business cycle theory of wesley mitchell. Journal of Economic Issues, 35(1):85-97.

Solow, R. M. (1997). Is there a core of usable macroeconomics we should all believe in? The American Economic Review, 87(2):230-232.

Sombart, W. (1904). Versuch einer systematik der wirtschaftskrisen. Archiv für Sozialwissenschaft und Sozialpolitik, 19:1-21.

Spearman, C. (1987). The proof and measurement of association between two things. By C. Spearman, 1904. The American journal of psychology, 100(3-4):441-471.

Summers, L. H. (1986). Some skeptical observations on real business cycle theory. Federal Reserve Bank of Minneapolis Quarterly Review, 10:23-27.

White, H. (1980). A Heteroskedasticity-Consistent Covariance Matrix Estimator and a Direct Test for Heteroskedasticity. Econometrica, 48(4):81738 .

Woitek, U. (1997). Business Cycles. An International Comparison of Stylized Facts in a Historical Perspective. Physica, Heidelberg.

Zarnowitz, V. (1992). Business Cycles: Theory, History, Indicators, and Forecasting. NBER Book Series Studies in Business Cycles. University of Chicago Press, Chicago. 


\section{SCHRIFTENREIHE DES \\ PROMOTIONSSCHWERPUNKTS \\ GLOBALISIERUNG UND BESCHÄFTIGUNG}

Nr. 1/1998 Bernhard Holwegler und Hans-Michael Trautwein, Beschäftigungswirkungen der Internationalisierung, eine Studie aus- und einfließender Direktinvestitionen der Metall- und Elektroindustrie im Raum Stuttgart

Nr. 2/1998 Heinz-Peter Spahn, Heterogeneous Labour, the Unemployment Equilibrium, and the Natural Rate

Nr. 3/1998 Philip Arestis, Iris Biefang-Frisancho Mariscal and Harald Hagemann, Capital Shortage Unemployment in Germany and the UK

Nr. 4/1999 Theo Schewe, Full Employment in the Age of Globalisation? PoliticalEconomic Analysis of Effective Employment Policies in the Nineties. The Case of Norway.

Nr. 5/1999 Hagen Krämer, Dienstleistungen: Motor für Wachstum und Beschäftigung in Deutschland?

Nr. 6/1999 Jürgen Kromphardt, Lohnbildung und Beschäftigung

Nr. 7/1999 Ewald Walterskirchen, Beschäftigungspolitik in Österreich

Nr. 8/1999 Reiner Franke, Lohnzurückhaltung, Beschäftigung und (zu) einfache empirische Zusammenhänge

Nr. 9/1999 Peter Kalmbach, Implications of Integration for Wage Formation and Employment

Nr. 10/2000 Arne Heise, Theoretische Grundlagen einer Verhaltensabstimmung der makroökonomischen Politikträger

Nr. 11/2000 Eckhard Hein und Carsten Ochsen, Monetary Interest Rates, Income Shares, and Investment: Theory and Empirical Evidence for France, Germany, the UK, and the USA

Nr. 12/2000 Guntram R. M. Hepperle, Airbus - ein gelungenes Beispiel für beschäftigungsorientierte Industriepolitik?

Nr. 13/2000 Bernhard Holwegler, Implikationen der Technologiediffusion für technologische Arbeitslosigkeit

Nr. 14/2000 Markus Schreyer, Wachstum und Beschäftigung vor dem Hintergrund des Solowschen Produktivitätsparadoxons

Nr. 15/2000 Mauro Boianovsky, Some Cambridge Reactions to The General Theory: David Champernowne and Joan Robinson on Full Employment

Nr. 16/2001 Marc-Peter Radke, Law and Economics of Microsoft vs. U.S. Department of Justice: A New Economic Paradigm for Antitrust in Network Markets or Inefficient Lock-in of Antitrust Policy?

Nr. 17/2001 Daniel Hartmann, Taylor-Regel und amerikanische Geldpolitik 
Nr. 18/2002

Nr. 19/2002

Nr. 20/2004

Nr. 21/2004

Nr. $22 / 2005$

Nr. 23/2006

Nr. $24 / 2007$

Nr. $25 / 2007$

Nr. $26 / 2008$

Nr. 27/2009

Nr. $28 / 2009$

Nr. 29/2009

Nr. 30/2009

Nr. 31/2010

Nr. 32/2010

Nr. 33/2011

Nr. 34/2011

Nr. 35/2011

Nr. 36/2012

Nr. 37/2012

Nr. 38/2012
Jutta Maute, Stabilization via Currency Board

Daniel Hartmann, The Fed Strategy: Successful but Out-of-Date?

Dirk H. Ehnts, Spatial Decisions of Multinational Enterprises and their Effect on Local Firms

Theo Schewe, Makroökonomische Probleme des extensiven Rohstoffexports in einer entwickelten Volkswirtschaft - analysiert am Beispiel der norwegischen Erdölwirtschaft

Georg Erber \& Aida Sayed-Ahmed, Offshore Outsourcing - A global shift in the present IT industry

Deborah Schöller, Service Offshoring: A Challenge for Employment? Evidence from Germany

Ralf Rukwid, Arbeitslosigkeit und Lohnspreizung - Empirische Befunde zur Arbeitsmarktsituation gering Qualifizierter in Deutschland

Julian P. Christ, Varieties of Systems of Innovation: A Survey of their Evolution in Growth Theory and Economic Geography

Andreja Benković \& Juan Felipe Mejía, Tourism as a Driver of Economic Development: The Colombian Experience

Julian P. Christ \& André P. Slowak, Standard-Setting and Knowledge Dynamics in Innovation Clusters

Constanze Dobler, The Impact of Institutions, Culture, and Religion on Per Capita Income

Julian P. Christ \& André P. Slowak, Why Blu-ray vs. HD-DVD is not VHS vs. Betamax: The Co-evolution of Standard-setting Consortia

Patricia Hofmann, Die nеме nеuе Außenhandelstheorie: das Melitz-Modell

Julian P. Christ, The Geography and Co-location of EuropeanTechnologyspecific Co-inventorship Networks

Julian P. Christ, Geographic Concentration and Spatial Inequality: Two Decades of EPO Patenting at the Level of European Micro Regions

Finn Marten Körner, An Equilibrium Model of 'Global Imbalances' Revisited

Constanze Dobler \& Harald Hagemann, Economic Growth in the Post-Socialist Russian Federation after 1991: The Role of Institutions

Constanze Dobler, Instability, Economic Stagnation and the Role of Islam in the North Caucasus

Georg Erber und Harald Hagemann, Wachstums- und Investitionsdynamik in Deutschland

Ralf Rukwid, Grenzen der Bildungsexpansion? Ausbildungsinadäquate Beschäftigung von Ausbildungs- und Hochschulabsolventen in Deutschland Vadim Kufenko, Empirical Analysis of Regional Economic Performance in Russia: Human Capital Perspective 
Nr. 39/2013 Harald Hagemann und Vadim Kufenko, The Political Kuznets Curve for Russia: Income Inequality, Rent Seeking Regional Elites and Empirical Determinants of Protests during 2011/2012

Nr. 40/2014 Danila Raskov und Vadim Kufenko, The Role of Old Believers' Enterprises: Evidence from the Nineteenth Century Moscow Textile Industry

Nr. 41/2014 Harald Hagemann, Georg Erber, Niels Geiger, Johannes Schwarzer und Oliver Zwiessler, Wachstums- und Investitionsdynamik in Deutschland

Nr. 42/2015 Vincent Geloso und Vadim Kufenko, Malthusian Pressures: Empirical Evidence from a Frontier Economy

Nr. 43/2015 Christine Clement, The Formal-Informal Economy Dualism in a Retrospective of Economic Thought since the 1940s

Nr. 44/2015 Niels Geiger, The Rise of Behavioural Economics: A Quantitative Assessment

Nr. 45/2015 Vadim Kufenko und Niels Geiger, Stylized Facts of the Business Cycle: Universal Phenomenon, or Institutionally Determined? 
Die Ursachen der gegenwärtig hohen Arbeitslosigkeit in einigen europäischen Ländern sind nicht allein in 'Funktionsproblemen des Arbeitsmarktes' zu suchen, sondern auch in Nachfrage- und Angebotsentwicklungen auf Güter- und Finanzmärkten. Im Promotionsschwerpunkt Globalisierung und Beschäftigung werden daher Dissertationsvorhaben gefördert, in denen die Beschäftigungseffekte gesamtwirtschaftlicher Entwicklungen untersucht werden - beispielsweise von neuen Technologien, von Prozessen der Internationalisierung und Systemtransformation, von marktseitigen Finanzierungsbeschränkungen oder von unterschiedlichen Strategien der Fiskal-, Geld- und Währungspolitik.

Die Betreuung und Vernetzung der Arbeiten im Promotionsschwerpunkt entspricht der Arbeitsweise eines Graduiertenkollegs. Betreuer des Schwerpunkts und Herausgeber der Schriftenreihe sind folgende Hochschullehrer:

Prof. Dr. Harald Hagemann

Institut für Volkswirtschaftslehre $(520 \mathrm{H})$

Universität Hohenheim

D-70593 Stuttgart

Prof. Dr. Heinz-Peter Spahn

Institut für Volkswirtschaftslehre (520A)

Universität Hohenheim

D-70593 Stuttgart

Prof. Dr. Hans-Michael Trautwein

Fakultät II - Institut für Volkswirtschaftslehre

Carl von Ossietzky Universität

D-26111 Oldenburg harald.hagemann@uni-hohenheim.de

peter.spahn@uni-hohenheim.de

michael.trautwein@uni-oldenburg.de

Dissertationsprojekte im Schwerpunkt können durch Promotionsstipendien des Evangelischen Studienwerks e.V. Villigst gefördert werden. Bewerbungsunterlagen können unter folgender Adresse angefordert werden:

Evangelisches Studienwerk e.V.

Promotionsförderung

Iserlohner Str. 25

58239 Schwerte

Tel.: 02304/755-215, Fax: 02304/755-250

Weitere Informationen zum Promotionsschwerpunkt sowie die Diskussionsbeiträge der Violetten Reihe im PDF-Format finden sich im Internet unter der Adresse:

http://www.globalization-and-employment.de 